\title{
Habitat use by the globally endangered Hinde's Babbler Turdoides hindei and its sympatric relative, the Northern Pied Babbler T. hypoleucus
}

\author{
PETER NJOROGE, LEON A. BENNUN and LUC LENS
}

\section{Summary}

We examined and compared territoriality and habitat use of two congeneric babbler species in Kirinyaga district, central Kenya, with the aim of explaining their differences in global conservation status. Hinde's Babbler Turdoides hindei is a scarce, globally Endangered species whereas Northern Pied Babbler T. hypoleucus is much more abundant and widespread, and occurs throughout the range of Hinde's Babbler. Our findings suggested a lack of flexibility in the choice of habitat by Hinde's Babbler, whose territories were centred on a scarce habitat type: Lantana thickets in river valleys or near swamps. The two species showed similar daily foraging ranges but Hinde's Babbler occupied smaller group territories, whose size was not related to group size. Aggressive encounters between the two species occurred over shared feeding grounds, all of which were initiated and won by Hinde's Babbler. Its dependence on Lantana thickets makes Hinde's Babbler highly susceptible to further habitat loss within its range.

\section{Introduction}

Populations of many organisms may appear to survive despite large-scale habitat destruction (Brooks and Balmford 1996). However, their risk of extinction is often greatly increased through the effects of demographic and environmental stochasticity, the reduction in quality of remaining habitat patches (see Caughley 1994) and loss of genetic variation in isolated populations (Soule 1987, Dhondt 1996). The vulnerability of a particular species to these factors is linked to its ecology: its (meta)-population dynamics, habitat preferences and behavioural traits (e.g. Lacy 1987, Soulé 1987; but see Caughley 1994). For effective conservation of a threatened species, detailed knowledge of its ecology is required.

Hinde's Babbler Turdoides hindei is a poorly known Kenyan endemic bird that is listed as globally Endangered (Collar and Stuart 1985, Collar et al. 1994). It is restricted to a small area around Mt Kenya (Plumb 1979) that has been extensively modified in recent decades by agricultural development (Lewis 1984, Turner 1992). The bird now exists at low densities in river valleys containing patches of exotic or indigenous thicket, where its breeding success is poor (Njoroge and Bennun, in press, Njoroge and Mutinda, 1996). 
This is in contrast to its close relative, the sympatric Northern Pied Babbler Turdoides hypoleucus, also endemic to the East African region (Turner 1977). Both species live in group territories and are cooperative breeders (Plumb 1979, Njoroge and Mutinda, 1996). The Northern Pied Babbler has a larger global distribution and is also much more widespread and numerous than Hinde's Babbler within their joint range; for example, it thrives in some surburban areas of the capital city, Nairobi (Lewis and Pomeroy 1989). Can differences between the species in territoriality and/or habitat use, or potential competition for food or other resources, explain the disparity in their current status?

\section{Materials and methods}

Data were collected from September 1993 to January 1994 in a $36.6 \mathrm{~km}^{2}$ study area $\left(37^{\circ} 20^{\prime} \mathrm{E}, 0^{\circ} 30^{\prime} 38^{\prime \prime} \mathrm{S}\right.$; alt. $\left.1800 \mathrm{~m}\right)$ in Gichugu division of Kirinyaga District, Kenya. The study area was characterized by undulating ridges and valleys, and traversed by small streams which eventually drain into the Tana River. Much of the area was intensively cultivated, with maize and coffee the dominant crops. Swampy areas were dominated by Triumfetta macrophylla, Croton macrostachys and Cyperus rotundus, while small fallow areas were dominated by Lantana camara, an introduced weedy shrub. A few indigenous tree species (Barsamia abyssinica, Prunus africana, Ficus natalensis and Milletia dura) remained scattered over the study area. Habitats were grouped into five categories: (i) thickets (Lantana, Eucalyptus and swamps), (ii) food crops (maize and vegetables), (iii) coffee, (iv) banana, and (v) grass (including grassy areas interspersed with short herbs). After measuring dimensions on the ground with the use of a compass and tally counter (one pace was estimated to equal $0.8 \mathrm{~m}$ ), different habitat types were plotted on an enlarged topographical map $(1: 2,500)$. Whenever a territorial group moved for more than $20 \mathrm{~m}$ or between habitat types or both, its position was recorded on this map.

Fourteen Hinde's Babblers in five territorial groups were captured with mist-nets. Each individual was sexed, aged and colour-marked, and biometrics were taken using standard methods. Mean wing lengths of Hinde's Babbler recorded in the field and from specimens in the ornithological collection of the National Museums of Kenya were significantly smaller than those of Northern Pied Babbler (Hinde's Babbler field: mean $=100 \pm 4 \mathrm{~mm}($ S.D.),$n=14$; collection: mean $=101 \pm 2 \mathrm{~mm}$ (S.D.), $n=6$; Northern Pied Babbler collection: mean $=106 \pm$ $\left.5 \mathrm{~mm}(\mathrm{~S} . \mathrm{D}),. n=15 ; t_{33}=4.72, P<0.05\right)$. Thirty-one territorial groups of Hinde's Babbler were recorded within the study area. Of these, we studied five in detail, together with the three groups of Northern Pied Babbler whose territories overlapped those of our focal Hinde's Babbler groups. The day was divided into three standard observation sessions: morning o6hoo-1ohoo; midday, 10hoo14hoo; and afternoon, 14hoo-18hoo. Group territory size and mean area used during different times of the day were calculated using the non-parametric method of Jennrich and Turner (1969). In order to examine habitat preference, the availability of a particular habitat was estimated from its relative area within a minimum convex polygon home range (Mohr 1947). The expected proportion of usage of each habitat, if no habitat choice was observed based on relative area, 
was compared with the actual usage by using the Bonferroni inequality (Miller 1966; Neu et al. 1974) to construct simultaneous confidence intervals on the observed proportion of usage.

\section{Results}

Both species formed stable, territorial groups consisting of between 2 and 11 individuals (mean size: Hinde's Babbler: $4.5 \pm 1.8, n=31$; Northern Pied Babbler: $8.3 \pm 3.1, n=3$ ). While intraspecific aggression between two neighbouring groups was never observed, interspecific interactions over shared feeding grounds occurred: out of 17 interspecific encounters, aggressive interactions were observed in 12, all of which were initiated and won by Hinde's Babbler. Mean group territory size for our focal groups (total area occupied during the course of the study period) was smaller for Hinde's Babbler than for Northern Pied Babbler (Hinde's Babbler: mean $=3.75 \pm 1.61$ ha, $n=5$; Northern Pied Babbler: mean $=6.60 \pm 1.81$ ha, $n=3 ; t_{6}=5.55, P<0.01$ ). Territory size of Hinde's Babbler did not correlate with group size $(n=5, r=0.2, P>0.05)$. The mean territory area used per four-hour observation session did not differ between species, although it did differ between times of the day (Hinde's Babbler: 1.79 \pm 0.68 ha, $n=80$; Northern Pied Babbler: $2.54 \pm 0.68$ ha, $n=47$; Repeated Measures ANOVA: species $F_{1,2}=1.96, P>0.05 ;$ time $F_{2,4}=12.63 ; P<0.01$ ). Group members foraged over a wider area in the morning than during midday and afternoon (Hinde's Babbler: Morning, mean $=2.7 \pm 2.1$ ha, $n=29 ;$ Midday and afternoon, mean $=1.4 \pm$ 1.2 ha, $n=51$; Northern Pied Babbler: Morning, mean $=6.5 \pm 2.4$ ha, $n=17$; Midday and afternoon, mean $=6.9 \pm 3.5 \mathrm{ha}, n=30$ ), and this pattern did not differ between species (Repeated Measures ANOVA: species ${ }^{*}$ time $F_{2,4}=0.26 ; P>0.05$ ). Both species showed similar daily activity patterns: individuals left roost sites at dawn for the feeding grounds, and most of the mornings were spent feeding. During midday, groups concentrated around Lantana thickets, while during evening they fed close to their roosting sites before proceeding to their roosts at dusk. Pooling data for both species, mean area used per day did not correlate with overall territory size nor with group size $\left(n=8\right.$; territory size, $r^{2}=0.21, P>$ 0.05 ; group size, $r^{2}=0.03, P>0.05$ ).

Hinde's Babbler spent more time in thickets and less time in food crops compared with Northern Pied Babbler ( $t$-test for unequal variances: thickets, $t_{80.9}=$ 2.52, $P<0.01$; food crops, $t_{11.7}=2.73, P<0.01$ ), while time spent in other habitat types did not differ between the species (Figure 1). Although habitat use varied between territorial groups, some types were preferred consistently at species level (Figure 2). Overall, Hinde's Babbler used food crops, grass and coffee less often and thickets and banana more often than expected by chance, whereas Northern Pied Babbler frequented the available habitats roughly in the proportion that they were present, although with a preference for coffee. Although food crops were visited slightly less than expected by chance, Northern Pied Babbler groups spent nearly $60 \%$ of their time in this extensive type of habitat. Hinde's Babbler groups, in contrast, spent $70 \%$ of their time in thickets and coffee which made up only $40 \%$ of the total territory area (Figure 1). As a result, Northern Pied Babbler groups used a larger proportion of their territories during the course of the study period than did Hinde's Babbler groups. 


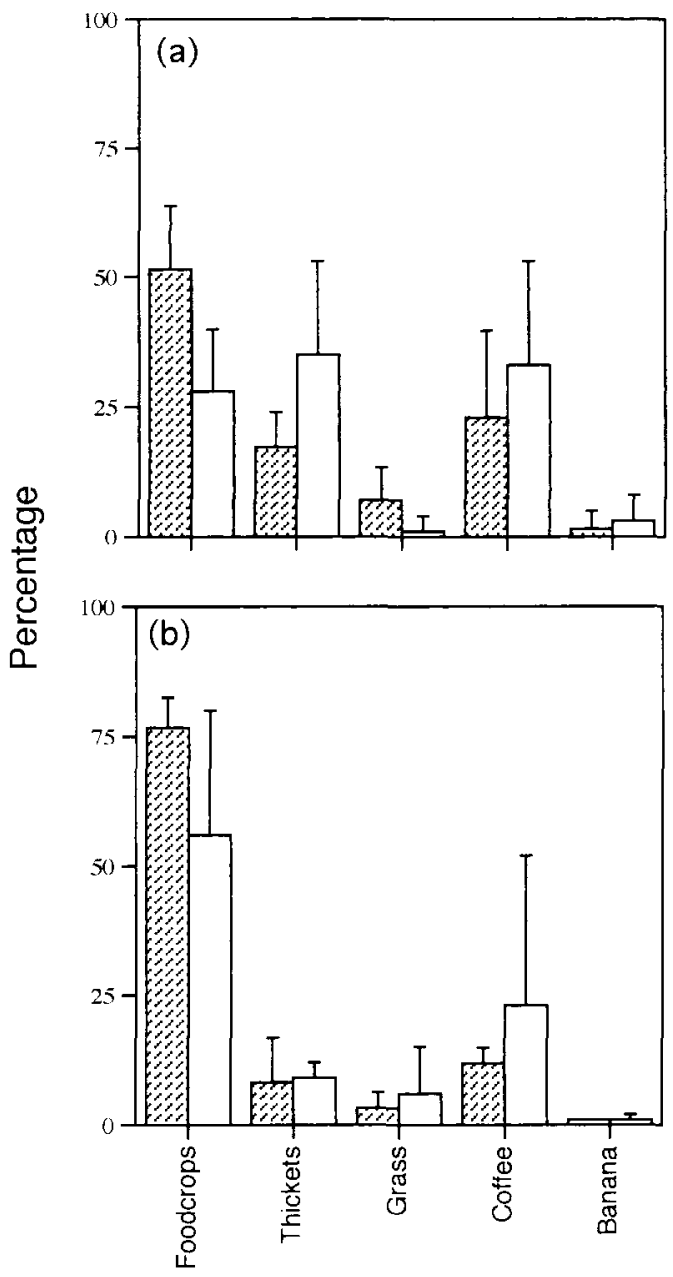

\section{Habitat type}

Figure 1. Territory composition versus time expenditure by (a) Hinde's Babbler and (b) Northern Pied Babbler; shaded bars, percentage of territory covered by habitat type, open bars, percentage of time spent in habitat type.

\section{Discussion}

Interspecific comparison of territoriality and habitat use revealed that Hinde's Babblers, compared with Northern Pied Babblers, (i) occupied smaller group territories, the size of which was not related to group size; (ii) had similar-sized daily ranges; and (iii) were more restricted to scarce habitat types within their territories. Furthermore, Hinde's Babbler group members consistently defended food resources against Northern Pied Babbler at shared feeding grounds, an energetically "costly" activity (Milinski and Parker 1991). All these findings suggest less efficient use of the available food resources (for example, through a 


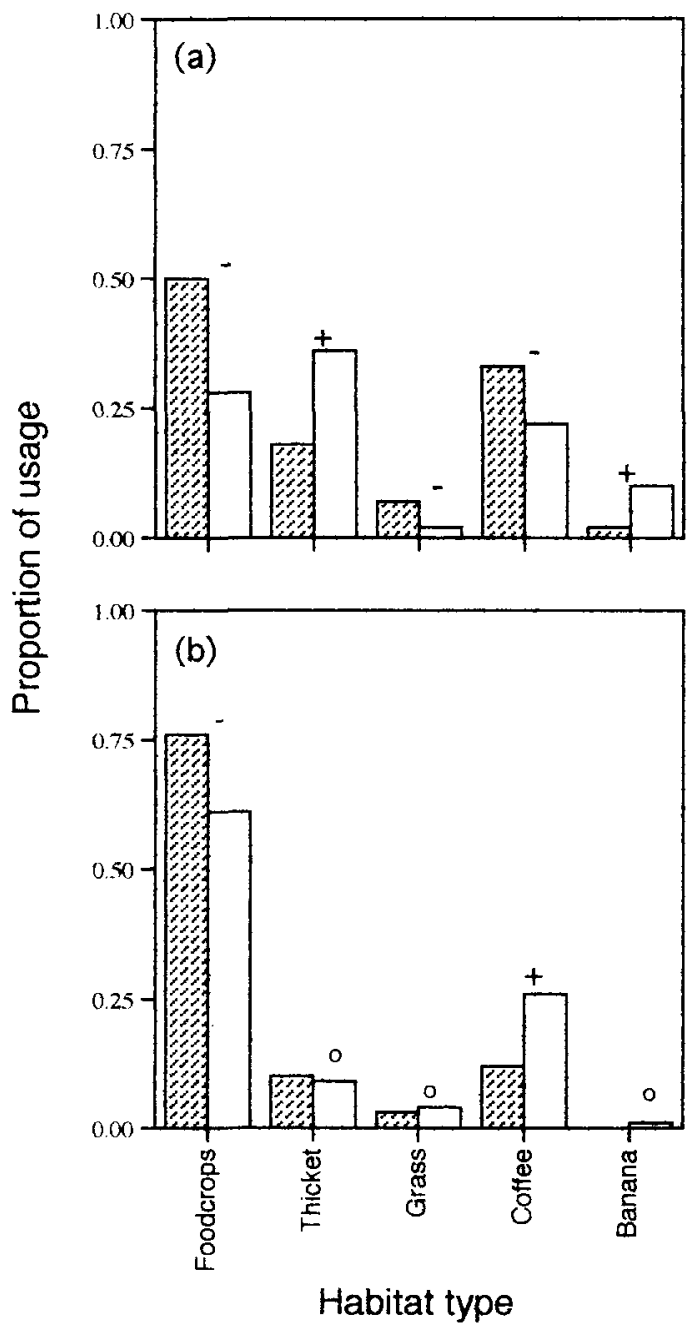

Figure 2. Habitat preference by (a) Hinde's Babbler and (b) Northern Pied Babbler; shaded bars, expected proportion, open bars, observed proportion; o/t/-, usage not different/more/ less than expected by chance as calculated from the Bonferroni inequality (see text for details).

higher rate of food depletion) and a lower flexibility in the choice of potential territory sites compared with Northern Pied Babbler. The pronounced confinement of Hinde's Babbler to Lantana thickets (Plumb 1979, Njoroge and Bennun, in press) together with the tendency of group territories to be centred on this type of habitat (P.N., pers. obs.) suggest that the species needs a critical amount of Lantana per territory. Hinde's Babbler territory size might thus largely be determined by the degree of patchiness of Lantana thickets. If so, a negative relationship between territory size and the proportion of Lantana it contains could be expected (see Lens 1992), but a larger sample size is required to test this prediction. 
Probably as a result of their strong confinement to Lantana thickets, Hinde's Babbler populations appear to be highly sedentary in the valleys in which they occur (Plumb 1979, P.N. unpublished). Lantana is an exotic shrub, so it appears that the species has re-adapted to use this type of habitat after the virtual disappearance of its natural habitat (possibly thickets along watercourses: Njoroge and Bennun, in press). Lantana patches made up less than $20 \%$ of the overall habitat within Hinde's Babbler territories. The presence and/or persistence of these patches in the future will depend entirely on human activities, in particular the amount of land left fallow or unweeded (Njoroge and Bennun, in press). Due to rapid human population growth (Jaetzold and Schmidt 1983), further fragmentation, resulting in an exponential increase in interpatch distance (Andrén 1994), is expected. This will undoubtedly increase the extinction risk for this species (Caughley 1994, Dhondt 1996). It is interesting to note that Hinde's Babbler now appears extinct at sites where it has been collected in the past, and where Northern Pied Babbler is still present (Turner 1992).

\section{Acknowledgements}

We are greatly indebted to David Mutinda for his tireless effort and assistance during data collection in the field, to the Ornithology Department of the National Museums of Kenya for logistical support, and to W.D. Koenig for helpful comments on the manuscript. Financial support was generously provided by BirdLife Kenya, Kenya Wildlife Service, The Royal Society for the Protection of Birds and the East African Wildlife Society to L.A.B. and P.N.

\section{References}

Andrén, H. (1994) Effects of habitat fragmentation on birds and mammals in landscapes with different proportions of suitable habitat: a review. Oikos 71: 355-366.

Brooks, T. and Balmford, A. (1996) Atlantic forest extinctions. Nature 380: 115.

Caughley, G. (1994) Directions in conservation biology. J. Anim. Ecol. 63: 215-244.

Collar, N. J. and Stuart, S. N. (1985) Threatened birds of Africa and related islands: The ICBP/ IUCN Red Data Book. Cambridge, U.K.: ICBP/IUCN.

Collar, N. J., Crosby, M. J. and Stattersfield, A. J. (1994) Birds to watch 2. The world list of threatened birds. Cambridge, U.K.: Birdlife International.

Dhondt, A. (1996) Molecular techniques in conservation and evolutionary biology: a quantum leap? Trends Ecol. Evol. 11: 147-148.

Jaetzold, R. and Schmidt, D. (1983) Farm management handbook of Kenya: East Kenya, II/B. Nairobi: Ministry of Agriculture, Kenya/GTZ, Germany.

Jennrich, R. T. and Turner, F. B. (1969) Measurement of a non-circular home range. $J$. Theor. Biol. 22: 227-237.

Lacy, R. C. (1987) Loss of genetic diversity from managed populations: interacting effects of drift, mutation, immigration, selection and population subdivision. Consero. Biol, 1: $143-158$.

Lens, L. (1992) Variation in coherence of crested tit winter flocks: an example of multivariate optimization. Acta Oecol. 13: 553-567.

Lewis, A. D. (1984) Hinde's Pied Babbler Turdoides hindei south of Machakos, Kenya. Scopus 8: $48-49$.

Lewis, A. and Pomeroy, D. E. (1989) A bird atlas of Kenya. Rotterdam: Balkema. 
Milinski, M. and Parker, G. A. (1991) Competition for resources. Pp. 137-168 in J. R. Krebs and N. B. Davies, eds. Behavioural ecology: an evolutionary approach, 3rd edition. Oxford: Blackwell Scientific Publications.

Miller, R. C. (1966) Simultaneous statistical inferences. New York: McGraw-Hill.

Mohr, C. O. (1947) Table of equivalent populations of Northern American small mammals. Am. Midl. Nat. 37: 223-249.

Neu, C. W., Byers, C. R. and Peek, J. M. (1974) A technique for analysis of utilization-availability data. f. Wildl. Mgmt. 38: 541-545.

Njoroge, P. and Bennun, L. A. (1996) Status and conservation of Hinde's Babbler Turdoides hindei, a threatened species in an agricultural landscape. Ostrich (Suppl). 67:170-172

Njoroge, P. and Mutinda, D. (in press) Notes on nesting of Hinde's Babbler Turdoides hindei and Northern Pied Babbler T. hypoleucus in Central Kenya. Ostrich.

Plumb, W. J. (1979) Observations on Hinde's Pied Babbler Turdoides hindei. Scopus 3: 61-67.

Soulé, M. E. (1987) Viable populations for conservation. Cambridge, U.K.: Cambridge University Press.

Turner, D. A. (1977) Status and distribution of East African endemic species. Scopus 1: 1-11.

Turner, D. (1992) Threatened birds of Kenya 2: Hinde's Pied Babbler. Kenya Birds 1: 46-47.

PETER NJOROGE, LEON A. BENNUN

National Museums of Kenya, Department of Ornithology, P. O. Box 40658, Nairobi, Kenya

\section{LUC LENS}

Department of Biology, Laboratory for Animal Ecology, University of Antwerp (UIA), B-2610 Wilrijk, Belgium 